\title{
La pandemia sanitaria, económica y social: Discurso presidencial chileno frente a la COVID-19
}

\author{
The health, economic and social pandemic: \\ Chilean presidential speech against COVID-19
}

\author{
Andrea Gartenlaub-González ${ }^{1}$ Rodolfo Arenas ${ }^{2}$
}

Cómo citar este artículo: Gartenlaub-González, A., Arenas, R. (2021). La pandemia sanitaria, económica y social: Discurso presidencial chileno frente a la COVID-19. Revista de Ciencias Sociales Ambos Mundos, (2), 91-103. https://doi.org/10.14198/ambos.20980

\begin{abstract}
Resumen
El texto revisa los discursos del presidente chileno Sebastián Piñera durante los meses de marzo a octubre del año 2020 , en medio del desarrollo de la crisis sanitaria producida por la COVID-19. En sus dos presidencia dirigiendo el país andino (2010-2014 / 2018-2022) Piñera ha debido sortear varias crisis sociales: un movimiento estudiantil, entre 2011 y 2012 ; un estallido de violencia social, en octubre de 2019, y luego la llegada de la COVID-19, en marzo de 2020. Dentro de este contexto el objetivo del artículo es establecer cuáles fueron los elementos discursivos más relevantes dentro del período de crisis sanitaria. Para ello se utilizaron conceptos provenientes de la teoría de representación social y del análisis político del discurso para analizar un conjunto de 27 discursos. El resultado muestra que la crisis de la COVID-19 se utilizó como una oportunidad para reforzar los fundamentos programáticos e ideológicos de la coalición gobernante, con el aval de la eficiencia, la idea de patria y referencias religiosas. Se concluye que el discurso de Piñera constituye un intento de manejar la agenda pública y política basado en la estrategia retórica del devil-angel shift.
\end{abstract}

Palabras claves: Publicidad gubernamental; Comunicación política; Publicación oficial; Liderazgo político; Pandemias.

Abstract

This text reviews the speeches of Chilean President Sebastián Piñera from March to October 2020, amid the development of the health crisis produced by COVID-19. During his two presidencies directing the Andean country (2010-2014 / 20182022), Piñera has had to overcome several social crises: a student protest, between 2011 and 2012; an outbreak of urban violence, in October 2019, and then the arrival of COVID-19, in March 2020. Within this context, the objective of this article is to establish which were the most relevant discursive elements within the period of the health crisis. For this, concepts from the theory of social representation and political discourse analysis were used to analyze a set of 27 discourses. The result shows that the COVID-19 crisis was used as an opportunity to reinforce the programmatic and ideological foundations of the ruling coalition, with the endorsement of efficiency, the idea of homeland and religious references. It is concluded that Piñera's speech constitutes an attempt to manage the public and political agenda based on the rhetorical strategy of the devil-angel shift.

Keywords: Government publicity; Political communication; Public information.

1. Andrea Gartenlaub-González, Universidad de Las Américas, Chile. agartenlaub@udla.cl https://orcid.org/0000-0002-2136-0422

2. Rodolfo Arenas, Universidad de Las Américas, Chile. rarenas@udla.cl https://orcid.org/0000-0001-5328-4674

Fecha recepción: 22/09/2021, Fecha aceptación: 25/10/2021

Licencia: Este trabajo está sujeto a una licencia de Reconocimiento 4.0 Internacional de Creative Commons (CC BY 4.0).

https://creativecommons.org/licenses/by/4.0/ 


\section{INTRODUCCIÓN}

Sebastián Piñera sucedió en la presidencia de Chile a la socialista Michelle Bachelet en marzo de 2018. Su segundo gobierno se inscribía dentro de la llamada ola conservadora latinoamericana, en que varios gobiernos de la región giraron hacia administraciones de derecha, tras décadas de gobiernos de izquierdas y socialdemócratas.

En medio de su segundo mandato, Piñera -octubre de 2019- debió enfrentar una crisis social inédita para la historia reciente del país, con marchas multitudinarias y una insurrección popular. El detonante de esta explosión social ha tratado de explicarse por varios factores, pero principalmente por la desigualdad económica en una nación que posee una altísima concentración de ingresos en que el $1 \%$ de su población más rica reúne el $26,5 \%$ de su Producto Interno Bruto (CEPAL, 2019).

Paralelamente, en diciembre de 2019, en China, se detectó un nuevo virus respiratorio: el SARSCoV-2, cuya rápida propagación hizo que -sólo tres meses después- la Organización Mundial de la Salud la decretara como una pandemia mundial. Durante los meses de enero y febrero de 2020 , nuestro país pasó de trabajar en una planificación preventiva, a cambiar su situación sanitaria con la detección de los primeros contagios, y luego, anunciar el 21 de marzo la primera muerte por el nuevo coronavirus (Ministerio de Salud, 2020).

La crisis social quedó en suspenso. El 14 de marzo el gobierno suspendió las actividades masivas. Al día siguiente, las medidas de restricción de movilidad se incrementaron con cuarentenas locales, aduanas sanitarias y la suspensión de clases presenciales para todos los niveles. Sin mediar intermedios, de la crisis social se pasó a la crisis sanitaria.

\section{ANTECEDENTES DEL CASO}

\subsection{La derecha chilena y la posición neoliberal-conservadora de Sebastián Piñera}

Distintas sensibilidades políticas conviven en la actual coalición de gobierno conformada por partidos de centro-derecha y derecha. En este conglomerado interactúan diferentes tradiciones políticas -a veces antitéticas-, desde una derecha liberal representada por partidos como Evópoli, y el ala liberal, de Renovación Nacional, partido integrado por las nuevas generaciones de antiguos latifundistas, me- dianos empresarios, y profesionales. Mientras en su polo más extremo, se ubican sectores conservadores, de estilo clientelar y corte popular, en el partido Unión Demócrata Independiente, y nuevos nacionalistas en el Partido Acción Republicana. Electoralmente y discursivamente se organizan -además- en un grupo transversal de parlamentarios de corte más pragmático y con una agenda de estilo socialcristiana. Debido a su heterogeneidad, tanto liberales, neoliberales-económicos, conservadores y facciones con perspectiva social forman alianzas coyunturales que no responden necesariamente a partidos específicos.

Dentro de este conglomerado, Piñera se ubica entre dos tradiciones: la conservadora en aspectos culturales: que reflejan en las objetivaciones referidas al concepto de familia (Gartenlaub y Valenzuela, 2019), patriotismo y un especial énfasis por reforzar el orden social; y la tradición económica de corte neoliberal, establecida fuertemente en este sector político durante la dictadura militar. Este eje económico tiene como característica principal mantener los principios neoliberales en el sistema económi$\mathrm{CO}^{1}$, en términos hegemónicos ha organizado al país en un determinado tipo de orden, con una estructura institucional donde lo económico subordina a la política. Este orden se ha mantenido vigente durante los gobiernos de centroizquierda (1989-2010), Ios cuales realizaron distintas correcciones pero siempre dentro del margen de lo que conocemos como "modelo neoliberal" (Garretón, 2012).

Sebastián Piñera en sus administraciones como presidente de Chile ha establecido estrategias comunicacionales que juegan con la idea de la "refundación", como la idea de crear una Nueva Derecha (en su primer mandato) (Alenda, Gartenlaub y Fischer, 2020) y, para su segundo mandato, la re-visitación de otra idea, la de los "grandes consensos".

\subsection{Los discursos del presidente: el recurso del enemigo poderoso}

En sus dos administraciones (de 2010 a 2014 y desde 2018 hasta la fecha), el presidente Piñera ha experimentado dificultades para desarrollar su programa de gobierno. Durante su primer manda-

1. Nace a partir de la adopción, entre otros aspectos, de la teoría monetarista de Friedman y Harberger, y a través de generaciones de economistas chilenos que graduados en la Escuela de Economía de Chicago. 
to el relato fue denominado como Nueva Derecha, un leitmotiv que promovía una derecha más inclusiva con valores posmateriales (Inglehart y Welzel, 2005) o "más moderada" (Madariaga y Rovira Kaltwasser 2020). Esta propuesta tuvo por objetivo atraer un electorado joven y menos ideológico y ampliar la visión conservadora que caracteriza al sector (Gartenlaub-González, 2018). No obstante, este intento fue desechado por el gobierno tras las manifestaciones multitudinarias de estudiantes que en 2011 solicitaban educación universitaria gratuita, la que concitó gran adhesión (Segovia y Gamboa 2012; Durán Migliardi 2012; Montero et al., 2017; Paredes y Otárola 2019).

El discurso presidencial en esta coyuntura estableció un intento de deslegitimación de los problemas estudiantiles denunciados, maximizando los inconvenientes de las manifestaciones. La estrategia discursiva apuntó a justificar la propuesta ideológica de su sector, créditos blandos, desestimando becas a través de subsidios. Pese a propuestas de búsqueda de acuerdos y un uso inclusivo del lenguaje, el gobierno buscó siempre consolidar su agenda educacional (Araya, 2014). A nivel hegemónico, en esta ocasión, el gobierno respondía la demanda ciudadana instalando una "dicotomización entre derechos/deberes permitía al oficialismo agenciarse en una posición de defensa de la estabilidad estructural, de racionalidad y de posibilismo congruente con su perfilamiento" (Duran Migliardi, 2020, p. 94).

En su segunda administración, el relato político se estableció desde un inicio en instalar un "gobierno de refundación". Esta vez el discurso deseaba equipar su gobierno con la presidencia de Patricio Aylwin, presidente que inauguró el retorno a la democracia en 1989 tras la dictadura militar, cuando el principal mecanismo de resolución de conflictos políticos fue el establecimiento de "consensos" entre elites políticas, militares y económicas.

Durante la primera etapa de su segundo mandato, a la idea de refundación se sumó un discurso centrado en la eficiencia administrativa. En ese momento, su propuesta de relato mostraba un deseo de trascender a la gestión local, con foco, antes de la crisis social, en movilizar recursos hacia un posible liderazgo en la agenda de política exterior (enfrentar al régimen venezolano, o encabezar el Foro de Cooperación Económica Asia-Pacífico 2019) y como promotor de temáticas medioambientales (al organizar $25^{\circ}$ Convención Marco de Naciones Unidas sobre el Cambio Climático).

Sin embargo, la crisis social de octubre de 2019 puso en entredicho ese perfil. La agenda del gobier- no se desplazó a los problemas internos y, ante la sorpresa de lo masivo y radical de las protestas, el discurso experimentó un giro hacia un repertorio bélico, con referencias a un "enemigo poderoso" (Navarro y Tromben, 2019). Este énfasis inicial, fue dando paso gradualmente a una aceptación de las reivindicaciones de la movilización, llegando incluso a reconocer insuficiencias del modelo económico y aceptando la posibilidad de modificar la Constitución Política de 1980, vigente en Chile desde la dictadura militar.

\section{OBJETIVOS}

Sebastián Piñera enfrentó situaciones de crisis en los segundos años de sus dos mandatos -2011 y 2019. El primer supuesto de este trabajo apunta a que, frente a cada nueva situación crítica, el discurso presidencial se mostrará reactivo, tal como frente a las demandas del movimiento estudiantil de 2011 y durante el levantamiento social de octubre 2019, y el año 2020, frente a la pandemia. Bajo ese supuesto, se propone como objetivo principal de este texto analizar las unidades de sentido que componen los discursos del presidente Piñera, en el período de crisis sanitaria correspondiente a su segundo mandato.

\section{PROPUESTA METODOLÓGICA}

\subsection{Comunicación política: Los objetos, las herramientas}

Los análisis en el ámbito de la comunicación política tienen diferentes objetos de estudio. Contemplan el flujo comunicacional que emiten los gobiernos hacia los electores; pero también las comunicaciones entre los grupos políticos y a los medios de comunicación en su rol para la conformación de la opinión pública.

El campo de la comunicación política tiene distintas fuentes metodológicas. Ello porque recurre a herramientas venidas desde las disciplinas de la lingüística, semiótica, hermenéutica, retórica y aproximaciones de estudios humanísticos y sociales -filosofía, historia, ciencias políticas, sociología- (Gutiérrez, 2007, pp. 89-91). En Iberoamérica, esta tradición cuenta con más de cuatro décadas, pudiendo rastrearse desde los trabajos de Verón y Munizaga en los 70 s y 80 s. Labor que se vio poten- 
ciada por los procesos de retorno a la democracia ocurridos en la última parte del siglo XX (Navarro y Tromben, 2019, p. 296; Pérez, 2014, p. 17).

Dentro de este entorno, el presente trabajo se inscribe en una metodología cualitativa, que recoge aportes de las disciplinas del lenguaje y de la ciencia política, y asume como objeto de estudio los discursos gubernamentales, específicamente, las alocuciones presidenciales realizadas durante la pandemia del 2020.

\subsection{Dos enfoques de análisis: La representación social y el análisis político del discurso}

Se propone un estudio cualitativo para interpretar los discursos emitidos por el presidente entre marzo y octubre de 2020.

Para esto se emplearon conceptos que vienen de dos enfoques teóricos distintos: el primero, el concepto de representación social, y el segundo, el de articulación hegemónica proveniente del Análisis Político del Discurso.

El primer enfoque de análisis es el concepto de representación social, entendido como una visión de la comunicación cotidiana en relación quiasmáti$\mathrm{ca}^{2}$ con los hechos sociales que son sus referentes. La teoría de las representaciones sociales establece que existe una forma de pensamiento social o colectivo mediante el cual los individuos obtienen cierta percepción común de la realidad y además, actúan en relación a ella (Lara, 2005b).

La representación social, a juicio de Moscovici, se entiende como "una visión de la comunicación y el pensamiento cotidianos del mundo actual y un análisis de hechos anónimos que son su con-

2. Acerca del esquema del quiasmo: "Al contrario de los esquemas dicotómicos, que conciben las relaciones en términos de exclusión, exterioridad y causalidad mecánica y lineal, el esquema del quiasmo permite pensar la dualidad como una unidad en proceso, en devenir. En palabras del autor, "pensar la dualidad como tal significa que ella no puede ser pensada ni en función de los elementos que la componen (dualismo metafísico) $n$ tampoco en función de una unidad trascendente que aparece como anterior al desdoblamiento (monismo teológico o metafísico) o como resultado de una reunificación postrera y extrínseca (monismo dialéctico)" (Ralón de Walton, 2014, p.171). traparte" (Moscovici en Lara, ${ }^{3} 2005$ b, p. 86). Esta elaboración se desarrolla en torno a dos procesos: la objetivación y el anclaje. El primero de ellos apunta a la estructuración, al acopio de significados que comuniquen un cierto entendimiento de la realidad social y que aspira a ser compartido. El segundo, la integración, vincula las construcciones anteriores; a establecer una nueva aspiración de sentido, a hacerla comprensible y plausible (Lara 2005a, pp. 87-89). En su conjunto, la objetivación como proyecto de interpretación social y el anclaje en cuanto esfuerzo de validación, tienden a instalar, con aspiraciones hegemónicas, un sistema de pensamiento particular en un espacio donde ya conviven otras lecturas de la realidad, las que se buscan justificar, complementar o reemplazar. El resultado posible del conocimiento que se logra, se hace a partir del análisis endógeno y la comunicación de masas (Lara, 2005b).

El segundo enfoque de análisis, y el principal que guía este trabajo, es el del Análisis Político del Discurso del investigador argentino Hernán Fair, construido partir de los trabajos del también argentino Ernesto Laclau y la belga Chantal Mouffe, y su Teoría Política del Discurso. Esta perspectiva presenta una epistemología posestructuralista y construccionista social, que propone entender la sociedad como una disputa discursiva (Fair, 2014).

La concepción del Análisis Político del Discurso (en adelante, APD) (Fair, 2019), describe el discurso político mediante tres niveles interpretativos:

1. Las implicaciones y contradicciones, que apuntan a establecer vínculos positivos (orden-crecimiento), negativos (desorden-pobreza) o conflictuados (desarrollo-populismo).

2. Luego, las trayectorias consideran la formulación de tendencias y de sus posibles modulaciones (modificaciones de principios argumentales).

3. Finalmente, el tercero, recoge la hipótesis hegemónica, la valoración final que se presenta como deseable.

De esta forma los discursos presidenciales que son analizados en unidades de sentido - mediante el APD determinan las implicancias o contradicciones que presuponen asignaciones valóricas,

3. El historiador revisa en el corrido (género musical mexicano) como la objetivación apunta a instalar, a través del denominado "narcorrido", una ética del narcotráfico, mediante anclajes el concepto de traición, el rechazo a la ilegalidad de la marihuana y personajes emblemáticos. 
demostrando la explicitación de logros para ostentar eficiencia, las que constituyen isotopías con otras alusiones similares en el mismo discurso o presentes en otro, para establecer tendencias que validan la administración gubernamental. Estas operaciones apuntan a develar la objetivación eficiente del gobierno y su anclaje por oposición a la negatividad de las demás opciones opositoras.

\subsection{Muestreo, corpus, y unidad de análisis}

Se estableció una selección del corpus por un muestreo intencionado que reunió tres criterios: tipológicos (discursos públicos), temático (pandemia) y temporal (entre los meses de marzo a octubre del año 2020), más las nociones metodológicas de relevancia y saturación, entendidas como la selección de unidades de sentido que brindan una mejor información, "ir a aquellas situaciones que probablemente entreguen información relevante", (Carrero, Soriano y Trinidad 2012, p. 25), hasta el límite de la repetición, "el muestreo teórico no acaba hasta que dejan de surgir nuevos datos" (Carrero, Soriano y Trinidad 2012, p. 25).

Esta selección se asumió la relevancia tácita que realiza la Presidencia de la República, utilizando los discursos publicados en la web Prensa Presidencia, oficina de propaganda gubernamental que selecciona las comunicaciones presidenciales que considera de mayor importancia (discursos, comunicados de prensa y fotografías). Desde esa fuente se recopilaron los discursos emitidos en hitos que se consideraron los más relevantes del período: las fases epidemiológicas 3 y 4 , la declaración de estado de catástrofe, intervenciones anunciando medidas sanitarias y económicas, cadenas nacionales de radio y televisión, alocuciones tangenciales vinculadas políticamente (exhortación al respeto de la Constitución) y actividades anexas relacionadas (recepción de equipos médicos, suspensión del alza de precios en la salud privada, centenario del expresidente chileno Patricio Aylwin).

El resultado de esta selección arrojó 27 discursos que se han analizado en unidades menores: unidades de sentido/ significado, contabilizándose en total 223 unidades de sentido particulares. Siendo estas unidades de sentido las unidades de análisis de este trabajo.

Según la literatura, una unidad de sentido puede ser entendida como un párrafo Toulmin (1958), ya que en el aparecen una "combinación de varios conceptos semánticamente convergentes" (Toulmin en Bustos Gisbert 2012, p. 63); o como dice Longacre (1979) puede ser "toda la información contenida que gira en torno a un concepto" (Longacre en Bustos Gisbert 2012, p. 63), por su parte Serafini (1989) señala que esta unidad es un "párrafo [que] le corresponde una sola idea" (Serafini en Bustos Gisbert 2012, p. 63).

\subsection{Metodología: análisis semiótico de unidades de sentido}

El trabajo de lectura semiótica de una estructura comunicacional constituye una labor topográfica, que parte desde la manifestación textual e intenta profundizar en los estratos sucesivos hasta llegar hasta el sentido último, la ideología, develando las valoraciones que guían las intenciones del mensaje, su elaboración y actualización enunciativa.

El objetivo de este trabajo no es reparar en unidades léxicas individuales, sino definir unidades de sentido que expliquen esta estructura profunda; primero, en un nivel político comunicacional donde se ubica la modalidad, es decir ese proceso en el cual "el sujeto enunciador introduce su 'huella' en el texto" (Aguado 2014, p. 117) es decir, le atribuye cualidades y/o valores de sentido: "la modalidad supone un acto de cualificación, esto es, la modalidad supone la atribución de cualidades a los distintos elementos del texto" (p. 118).

El segundo proceso corresponde al sistema de operaciones de esos valores, lo que permiten la transición de esos valores en oposiciones, o lo que hemos definido como devil-angel shift. En suma, el método de análisis comprende tres pasos para encontrar la estructura profunda de estos discursos:

a) A través de la lectura sucesivas de cada uno de los discursos, detectar distintas modalizaciones de las unidades de sentidos. Para luego, clasificarlas según valores de sentido compartido.

b) Definir la red de relaciones de las unidades de sentido, ya entendidas como valores de sentido (Definiéndose las siguientes Familia, Clase Media, Patria, Dios, Pandemia y Crisis Económica)

c) Finalmente, analizar el sistema de operaciones que organizan el paso de un valor de sentido a otro. (Familia $=$ Clase Media $=\mathrm{Pa}$ tria $=$ Orden; Dios = Orden; Sistema Económico $=$ Orden $/$ Pandemia $=$ Desorden; Crisis Económica $=$ Desorden) 


\section{ANÁLISIS DE RESULTADOS}

\subsection{Niveles de análisis}

En los mecanismos discursivos para la instalación del relato comunicacional del gobierno chileno durante el período de la crisis sanitaria y económica evidencian tres niveles:

- Comunicacional: necesidad de reforzar la agenda programática y legislativa inconclusa del gobierno, con ánimo de reencantar a la ciudadanía a través de un manejo eficaz de la crisis. - Interpretativo: construcción de una representación social en la definición de roles como familia, clase media, Dios, y los valores que éstos representan en el relato político analizado.

- Articulación: aspiración hegemónica de orden ideológico, en donde se ubica el recurso del devil-angel shift.

\subsection{Eficiencia y construcción del enemigo}

Como ya se señaló al principio de este texto, los gobiernos de Sebastián Piñera (2010-2014 / 2018 al presente) se ubican dentro de tradiciones ideológicas y programáticas donde hay dos elementos clave: el pensamiento económico-neoliberal y un esquema cultural conservador.

Por ejemplo, el concepto de "eficacia" aparece recurrentemente en sus discursos, desde su primer mandato, instalando en su relato gubernamental la idea de "eficiencia tecnocrática" (Funk, 2011; Varas, 2013; Duran Migliardi, 2020).

"Apenas conocimos los casos ocurridos en China, nuestro Gobierno inició su preparación para enfrentar adecuadamente esta enfermedad y proteger con eficacia la salud de todos los chilenos" (Prensa Presidencia, 2020, 13 de marzo).

[Tras evitar alza de seguros de salud privados] "... Quiero felicitar al ministro de Salud por una gestión hecha en forma oportuna y eficaz, y que significa una muy buena noticia para más de 3 millones de compatriotas" (Prensa Presidencia, 2020, $1^{\circ}$ de abril).

"Igual como la vacuna será la solución más eficaz y permanente para el Coronavirus, la recuperación y fortalecimiento de nuestra economía será la herramienta más eficaz y permanente para recuperar el 1.5 millones de empleos que hemos perdido" (Prensa Presidencia, 2020, 5 de julio)
Para el período analizado, estos ejes centrales se mantienen; pero se refuerza, con otros conceptos que respaldarán los resultados de la valoración "eficiente" de su gestión. Por ejemplo, su capacidad personal (un presidente que "se preocupa y se ocupa"); el apoyo de los ciudadanos "generosos" (profesionales de la Salud, Fuerzas Armadas, empleados públicos y empresarios); la apelación nacionalista, el mito del país "criado en la adversidad", y el concepto religioso, la "ayuda de Dios" 4 .

A nivel comunicacional e interpretativo el Ejecutivo construyó posiciones entre adversarios y aliados, conocido como el recurso del devil shift. El concepto fue acuñado por Sabatier et al. (1987) para indicar cómo actores políticos demonizan a sus oponentes: "Los actores políticos recuerdan las pérdidas más vívidamente que las ganancias políticas. Por lo tanto, temen a sus oponentes y tienden a verlos como más poderosos de lo que realmente son" (Fischer et al., 2015, p. 1).

Así, frases como "nos enfrentamos a un enemigo poderoso" (Piñera en octubre 2019, durante la crisis social) y "la pandemia es un enemigo invisible" (Piñera en mayo 2020, durante la crisis sanitaria), responden a sobreestimar la divergencia de valores y posiciones frente a sus adversarios. El actor político que utiliza esta estrategia discursiva caracteriza a lo que se le contrapone como una calamidad, se demoniza al adversario, en este punto es cuando estamos ante el nivel de articulación hegemónica.

En este devil shift los discursos presidenciales establecen un mundo de referencia en que él mismo se instala en el lado positivo, junto al personal de salud, gente anónima que lo respalda, las FF.AA. y el gran empresariado; incluso incluye a ciertos adversarios políticos -siempre que apoyen sus proyectos-. En este ámbito, pero en el ámbito de los valores: se ubican las libertades, los derechos, la salud, el estilo de vida que se debe recuperar, la felicidad e incluso a Dios. Al frente, en el sector adverso, se cuentan las dos pandemias (la COVID-19 y la recesión económica), "los ciudadanos que irresponsablemente" no acatan las disposiciones sanitarias y los sectores que cuestionan las medidas gubernamentales (partidos de oposición, gremios profesionales y ciudadanía crítica).

4. Chile se declara una república laica; sin embargo, los partidos de la coalición de gobierno mantienen relaciones históricas con la Iglesia Católica y, más recientemente, con los credos pentecostales. 
Además de la dimensión demonizada del adversario, por falta de unidad nacional y poca colaboración de ciudadanos, el presidente Piñera personaliza el enfrentamiento de la pandemia, condicionándolo a posibles resultados menos felices. En ese momento el gobierno realiza una apelación de unidad. La estrategia cambia a angel shift (Merry, 2019). Esta estrategia fue utilizada en la crisis social de noviembre de 2019, cuando todas las fuerzas políticas acordaron un itinerario para cambiar la Constitución. En marzo de 2020, la estrategia resulta similar: se solicita convergencia a los actores políticos y sociales externos al gobierno. Pero esta "buena causa" contiene una condición: el respaldo de la oposición política a su agenda. En suma, la eficacia del gobierno necesita un paso anterior, la necesidad de "aunar voluntades".

\section{"Quiero valorar y agradecer a todos quienes acudie- ron con buena voluntad y espíritu constructivo al llamado que hicimos (...) para construir un Acuerdo para proteger los ingresos de las familias y recupe- rar los empleos y la actividad de nuestra economía, dentro de un marco de uso eficaz y responsable de los recursos públicos que pertenecen a todos los chilenos (...). Este acuerdo es para la gente y rei- vindica el valor de la buena política que, en base al diálogo y la colaboración, logra buenos resultados" (Prensa Presidencia, 2020, 14 de junio).}

Esta insistencia en el requisito de un «gobierno de unidad» nace como una idea-fuerza dentro del programa de su segundo gobierno. Pero también, hay una razón práctica: la coalición oficialista no cuenta con mayoría parlamentaria y necesita crear alianzas con los sectores de centro y centroizquierda más proclives al modelo económico-neoliberal.

"No puedo dejar de preguntarme ¿qué nos diría [el] presidente Aylwin? Yo estoy seguro de que nos llamaría a ennoblecer la política, a buscar los caminos del diálogo y los acuerdos, a cultivar la amistad cívica, a ocuparnos de los más vulnerables y también a comprometernos con ese amor, compromiso por la patria y por todos nuestros compatriotas" (Prensa Presidencia, 2020, 4 de octubre).

La comparación con el gobierno de unidad de Patricio Aylwin (1989-1994), al inicio del período de restauración democrática, constituye un recurso retórico reforzado en el período de pandemia con una constante apelación a la unidad y a la «buena política». Esta estrategia intenta recuperar el cronograma de su gobierno y se intensifica tras la pérdida de control de la agenda legislativa desde la crisis de octubre 2019, en la cual debió pactar con la oposición la realización de un plebiscito para cambiar la Constitución.

Durante el período de pandemia, la necesidad de unidad se tradujo en contar con los votos necesarios para legislar acerca de un ingreso mínimo de emergencia -medida difícilmente rechazable por la oposición-. El presidente comparó este acuerdo con un enamoramiento.

«Vamos a promulgar dos nuevas leyes que son parte de un acuerdo. Un acuerdo que logramos con algunos partidos de la Oposición y con todos los partidos de Chile Vamos, y en que participaron en forma muy activa muchas personas, especialmente los parlamentarios de la Comisión de Hacienda, economistas y expertos (...). La actitud y la buena voluntad son un poco como el amor, cuesta definir cuando uno está enamorado, pero uno se da cuenta de inmediato cuando lo está. Lo mismo pasa con la buena voluntad» (Prensa Presidencia, 2020, 21 de junio).

La idea de unidad se fortalece con la conceptualización de un adversario en la pandemia, un «enemigo inmenso, silencioso". El gobierno proyecta un encantamiento al designar a esta lucha contra la pandemia como "el mayor reto en a lo menos un siglo".

En este punto, la estrategia de Piñera consiste en instalar un adversario, que unifique su relato, un devil-shift. Las alusiones a quienes no respaldan sus gestiones se instalan en la otredad, están fuera del ámbito de los receptores del discurso, no constituyen gente de "buena voluntad". Tal como, en su primera crisis, son recurrentes las metáforas bélicas, como un "ejército invisible" que lo apoya.

En suma, la metáfora del "enemigo poderoso" que resulta recurrente, había sido utilizada por Piñera -al menos tres veces- en distintas coyunturas anteriores a la crisis social de 2019 (Navarro y Tromben 2019, p. 309); sin embargo, el quiebre comunicacional que se produce con la crisis de octubre de 2019 lo agudiza.

\subsection{Clase media y familia}

A nivel comunicacional e interpretativo el discurso gubernamental se dirige hacia sujetos sociales específicos. El presidente le habla a la Nación, lo que une a los "chilenos"; pero también presenta una 
taxonomía conservadora: sujetos que viven en un Estado subsidiario, en una estructura familiar específica, y en un orden social que debe ser preservado.

Este es un orden político-económico. La manera de conceptualizar la sociedad se basa en el concepto 'clase social'. Los sujetos del discurso del presidente corresponden a la clase media o los sectores vulnerables. Cuando habla del impacto económico, principalmente, se refiere a las «familias y trabajadores, y a la gran, mediana y pequeña empresa". No hay alusiones a otros sujetos sociopolíticos más comunes en la retórica latinoamericana, como el pueblo, lo que es coherente con las tradiciones políticas que Sebastián Piñera representa. El presidente se dirige a la clase media y a los grupos socioeconómicos "menos favorecidos", debido a que ellos -hasta el año 2018-constituían el mayor caudal electoral de la centroderecha chilena (Morales y Cantillana, 2008; Castillo-Gallardo, 2014).

En vista del examen anterior, el discurso del presidente Piñera expresa un concepto clave en su propuesta: la capacidad de agencia de los individuos, que enfatiza la meritocracia como un valor de identificación para la clase media. Esta retórica que apela a la capacidad de "valerse por sí mismos" resulta relevante porque implica la no dependencia del Estado, en el sobreentendido de que eso sería un fracaso personal. El Estado solo debería preocuparse de las personas de menos recursos, los que no han podido insertarse adecuadamente en el sistema. Esta percepción sobre la ayuda estatal proviene del enfoque de las políticas sociales subsidiarias que refuerzan la focalización del beneficio social. En el período estudiado, este énfasis socioeconómico en la construcción de sujetos, se modula -además- hacia la responsabilidad sanitaria individual. El ciudadano que resulta capaz de cuidarse a sí mismo, en esta crisis y sin ayuda estatal, debería estar "orgulloso".

"Chile es un país mayoritariamente de clase media, la que ha progresado en base a su propio mérito, esfuerzo y trabajo. La clase media lo sabe y se siente orgullosa de sus logros" (Prensa Presidencia, 2020, 5 de julio)

Otro concepto usado a nivel comunicacional es la familia. En sus discursos, el país, Chile, representa una "gran familia", lo que corresponde a una modulación e interpretación paternalista. El presidente parece metamorfosearse en un padre que vela por sus hijos, pero que también los regaña si no responden con obediencia a sus desvelos.
"Chile es una familia y ninguna familia deja sola o desamparada a ninguno de sus integrantes. Por eso quiero ratificar el firme compromiso de acompañar y ayudar a todos y todas las personas y las familias que requieren ayuda" (Prensa Presidencia, 2020, 21 de junio).

"Sabemos que también existe un importante grupo de irresponsables que no las cumplen, poniendo en riesgo su salud y la salud de todos los demás y poniendo en riesgo también la vida de los grupos de alto riesgo" (Prensa Presidencia, 2020, 18 de junio).

Ambos sujetos, la clase media y la familia, corresponden a sujetos a los que tradicionalmente la derecha chilena apela en sus discursos. A este nivel la articulación hegemónica opera a través de las representaciones sociales del receptor del discurso presidencial. Se suman a ello, como se indicó, otros conceptos en sus discursos, como Dios y la unidad nacional. Ambos elementos, la religión católica y la Patria, también son elementos característicos de los discursos políticos desde estos partidos ubicados a la derecha del entorno ideológico.

"Tengo la convicción que, con el compromiso y apoyo de todos y con la ayuda de Dios, los chilenos sabremos, una vez más, como lo hemos hecho tantas veces en el pasado, enfrentar esta pandemia, superar estas adversidades, ponernos de pie y volver a caminar hacia un futuro más luminoso" (Prensa Presidencia, 2020, 5 de julio).

"Chile y los chilenos nos hemos forjado en la adversidad y somos hijos del rigor. En nuestra historia hemos recibido muchos golpes y enfrentado grandes desafíos. Pero siempre, siempre, hemos sabido ponernos de pie y retomar el camino" (Prensa Presidencia, 2020, 14 de junio).

En sus discursos, el presidente apunta a la construcción de un receptor partidario, en que quienes apoyan sus medidas están a un lado, el de la familia, las libertades y la felicidad; mientras que al frente se ubican los que no creen en la unidad, los que carecen de "buena voluntad", los que colaboran con el avance de la pandemia y conspiran contra la economía nacional. El concepto central estriba en entender que la salida correcta radica en el apoyo de las medidas gubernamentales, de otra manera se colabora con el virus, la pérdida del estilo de vida y el fracaso del modelo chileno. 
"Todos sabemos que el mejor camino (...) es con unidad, colaboración y grandeza... Con el apoyo de todos, con la luz de la esperanza y con la ayuda de Dios, podremos revivir nuestros sueños, realizar nuestros proyectos, volver a reunirnos con nuestros seres queridos y recuperar nuestras libertades y vidas" (Prensa Presidencia, 2020, 18 de junio).

En estas alocuciones vuelve a la idea de la unidad (angel shift) para dejar de lado las diferencias, en una apelación constante a la oposición para neutralizar el debate. La crisis social es un elemento latente que se encuentra contenida por la pandemia. En ese escenario, y a falta de medidas concretas para desactivar el conflicto, la estrategia comunicacional formula mensajes que apuntan a olvidar, o al menos posponer, la controversia. Para ello será necesario patriotismo y unirse bajo el liderazgo presidencial en apoyo de su agenda: «Dejar en cuarentena nuestras diferencias" (Prensa Presidencia, 2020, 30 de mayo).

\subsection{El nivel hegemónico de análisis. Múltiples pandemias y una solución}

A medida que las consecuencias de la pandemia se agravaron, con peores índices de contagio y mortalidad, la retórica del gobierno evolucionó. En el primer período -marzo y abril- los mensajes comunicacionales mostraron el supuesto éxito chileno con la eficiencia de la gestión gubernamental, ejemplificada con políticas sociales de apoyo financiero y sanitario, las que se autoevaluaron como superiores a países con mejores estándares económicos y el resto del América Latina.

"Sin este formidable esfuerzo, que continuaremos realizando sin pausa ni descanso, nuestro Sistema de Salud, al igual como ocurrió en muchos países desarrollados y de América Latina, habría colapsado hace mucho tiempo. Y, sin embargo, gracias al trabajo incansable, comprometido y valiente de los 360 mil trabajadores de la salud, la colaboración de todos los chilenos y el trabajo de nuestro Gobierno, nuestro Sistema de Salud, aunque con muchas dificultades, sigue prestando los servicios y atenciones de salud" (Prensa presidencia, 2020, 2 de junio).

Durante esta etapa se consideraron medidas incipientes de desconfinamiento, como el denominado Plan Retorno Seguro: "Tendremos que aprender a vi- vir en una Nueva Normalidad" (Prensa Presidencia, 2020, 19 de abril). Sin embargo, tanto el contagio como la letalidad del virus escalaron, por lo que se modificó la agenda. Pese a ello, la estrategia comunicacional se mantuvo: los discursos engarzan salud con orden, disciplina, felicidad, libertad y la buena política. El devil shift se hace más explícito: los divisionistas que propagan la enfermedad o dificultan las políticas de gobierno conducen al dolor y a la muerte.

La retórica de la enfermedad tiene un correlato equivalente con los problemas económicos. La pandemia sanitaria es lo mismo que la pandemia económica. Es el mismo adversario que debemos combatir.

"Protegerlos de la pandemia del coronavirus y protegiéndolos también de la pandemia social de la recesión que afecta al mundo entero" (Prensa Presidencia, 2020, 25 de junio).

Esta estrategia busca trasladar el desempleo, las quiebras de pequeñas empresas, las restricciones de libertades y restricciones de reunión y movilización suspendidos a dos causas, la llegada de la COVID-19, pero también por la inestabilidad del periodo inmediatamente anterior, la crisis social de octubre de 2019. Es aquí donde acuña un nuevo concepto: "la pandemia social».

"La Pandemia Sanitaria del Coronavirus y la Pandemia Social de la Recesión están afectando gravemente la salud de miles de compatriotas y los empleos e ingresos de millones de familias chilenas (...) Por estas razones nuestro Gobierno ha puesto en marcha una Red de Protección Sanitaria y una Red de Protección Social" (Prensa Presidencia, 2020, 22 de mayo).

Sobre esta construcción discursiva de (las) pandemia(s), el discurso instala una racionalidad tecnocrática (nivel hegemónico del discurso), en la que debe primar el conocimiento confiable, "técnico", instalándose como una salida sin alternativas.

Las soluciones que entrega el gobierno "Red de Protección Sanitaria y una Red de Protección Social" pueden aplacar todas las pandemias y hasta aliviar la "violencia" (que alude a la situación social de octubre) que habría afectado la economía nacional.

"Los chilenos hemos vivido tiempos muy difíciles debido a un conjunto de eventos y fenómenos. Hemos sido golpeados por una dura y extensa sequía que aún no nos da tregua. Hemos sido afectados 
por el estallido de violencia y las legítimas demandas sociales, que se generaron a partir del 18 de octubre. Hemos sido golpeados por la peor amenaza sanitaria de los últimos 100 años, representada por la Pandemia del Coronavirus. Y también, estamos siendo afectados por lo que se presagia será la peor recesión de la economía mundial desde la gran crisis de 1929" (Prensa Presidencia, 2020, 19 de abril).

De esta manera, el virus queda igualado a todos los factores que pudieran incidir en la situación económica. Este recurso se refuerza con una yuxtaposición metonímica arbitraria, cuando declara, al presentar medidas que irán en beneficio de la familia, lo hace en conjunto con la búsqueda de una solución política, de "un acuerdo". De nuevo, la opción de salida intenta ser única: para lograr los recursos que necesita la población, el camino correcto es, identificarse con la gestión del gobierno.

"En este acuerdo, tan esperado como urgente y necesario, concurrieron las voluntades y corazones de muchas personas y organizaciones" (Prensa Presidencia, 2020, 15 de junio).

Ambos recursos intentan construir operaciones hegemónicas, al plantearse como los únicos viables y demonizando a quienes no los acepten, caracterizándolos como funcionales a las pandemias, a la separación de las familias, a la pérdida de fuentes laborales, a los cambios forzados en el estilo de vida, al sufrimiento.

\section{CONCLUSIÓN: PANDEMIAS Y DEMONIOS}

El presidente Sebastián Piñera enfrenta la pandemia de la COVID-19 como una crisis que se instala dentro de una situación crítica anterior. De la crisis política de octubre de 2019 se pasa a la crisis de salud de marzo de 2020. Pero en vez de entender estos fenómenos como una sucesión, el presidente chileno construye una suerte de doble enemigo, la pandemia social y la pandemia sanitaria. Una metáfora que iguala ambas realidades, la amenaza por la enfermedad y la amenaza económica, y justifica la medida que se estime conveniente, pero también cualquier emplazamiento.

Frente a este devil shift, instala el protagonismo de la eficiencia. Donde los que respaldan ingresan, por oposición de contrarios, al ámbito de lo positivo: donde se encuentran la recuperación del estilo de vida, las inversiones, la salud, los ingresos, la libertad y la felicidad. En suma, un angel shift que se enfrenta al demonio de las pandemias, a la crisis social e incluso la sequía.

La apelación que se construye en los discursos apunta a una mirada focalizada a grupos de la sociedad. Se le habla principalmente a la "clase media", que aparece representada como el sector más afectado por la pandemia múltiple. El otro sujeto que se instala es la "familia". No en individuos, sino en un núcleo familiar entendido de manera tradicional, que constituye el espacio donde se reciben ingresos y radica la felicidad. Pero este recurso apelativo no se limita a este intento de aprobación, sino que crece hasta ser una identificación nacional, en que Chile representa "una gran familia", en que el presidente encarna un padre que vela por sus hijos. En la comunicación presidencial no aparecen individuos, ciudadanos o comunidades, sino familias, entendidas como representaciones de la sociedad.

La estrategia hegemónica se proyecta a partir de dos recursos discursivos. El devil shift que abarca todas las pandemias, incluso crisis anteriores, pero, a la vez, permite un angel shift que hace que la racionalidad tecnocrática sea la vía de alivio.

En suma, es esta estrategia: la yuxtaposición de discursos sobre las pandemias, la que podemos observar como estrategia comunicacional hacia un realineamiento de su programa de gobierno (instalación de la Red Clase Media Protegida); pero, sobre todo, apoyo a su gestión. El presidente Sebastián Piñera repite con la crisis sanitaria de 2020 , aunque esta vez sin claudicaciones en el discurso, su forma de enfrentar la crisis social de 2019, sus alocuciones operan con modificaciones tácticas; pero, su programa no cambia, sostiene su posición respecto del mantenimiento del orden económico-político a través de un juego comunicacional de opuestos: de chilenos-adversarios, familias-divisionistas, orden-pandemia, en suma, una lógica de ángeles y demonios.

\section{REFERENCIAS}

Aguado Terrón, J. M. (2004). Introducción a las Teorías de la Comunicación y la Información. Marín, Diego, Librero Editor, S.L.

Alenda, S., Gartenlaub, A. y Fischer, K (2020) Ganar la batalla de las ideas: el rol de los think tanks en la configuración de la nueva centro-derecha chilena. 
En S. Alenda, (ed.). Anatomía de la derecha chilena: Estado, mercado y valores en tiempos de cambio (pp. 119-156). Fondo de Cultura Económica.

Araya, C. y FaríAs, M. (2014). El movimiento estudiantil chileno del 2011 en intervenciones discursivas del presidente Piñera. Logos, Revista de Lingüística, Filosofía y Literatura, 24(1) 51-65. https://doi.org/10.15443/RL2405

Bustos Gisbert, J. M. (2012). Interpretación multifuncional del párrafo. ELUA: Estudios de Lingüística. (26), 55-88. https://doi.org/10.14198/ ELUA2012.26.03

Carrero, V., Soriano, R. y Trinidad, A. (2012). Teoría fundamentada: Grounded Theory. Centro de Investigaciones Sociológicas, Cuadernos Metodológicos 37. https://www.uv. mx/mie/files/2012/10/ LaConstrucciondelaTeoriadelAnalisilnterpretacional.pdf

Castillo-Gallardo, M. (2014). Clases medias y trabajadores frente a la política: sobre el ascenso electoral de la derecha en Chile. Universum, 29(2), 65-82. https://doi.org/10.4067/S071823762014000200006

CEPAL (2019). Panorama Social de América Latina 2019. Naciones Unidas.

DuRán Migliardi., C. (2020). La derecha y el abordaje discursivo del malestar social durante el primer gobierno de Sebastián Piñera, 2010-2014. Revista de Historia y Geografía, (42), 79-99. https:// doi.org/10.29344/07194145.42.2328

FAIR, H. (2014). Postulados epistemológicos para el desarrollo de un método de análisis socio-político del discurso desde la perspectiva de Laclau. Cinta Moebio, 51, 137-155. https://doi.org/10.4067/ S0717-554X2014000300003

Falr, H. (2019). Análisis Político del Discurso e investigación empírica: herramientas teóricas y estrategias metodológicas para estudiar identidades y procesos políticos desde América Latina. Ciencia Política, 14 (27), 47-90. https://doi.org/10.15446/ cp.v14n27.73323

FISCher, M., Ingold, K., Sciarini, P. y Varone, F. (2015). Dealing with Bad Guys: Actor- and Process-Level Determinants of the 'Devil Shift' in Policy Making. Journal of Public Policy, 1(2), 1-26. https://doi. org/10.1017/S0143814X15000021

Funk, R. (2011). El relato político en el primer año del gobierno de Piñera. Revista de Ciencia Política, 49(2), 151-159. https://doi.org/10.5354/07161077.2011.17318

GarRetón, M. A. (2012). Neoliberalismo corregido y progresismo limitado: Los gobiernos de la concertación en Chile, 1990-2010. Editorial Arcis.
Gartenlaub-GonzÁlez, A. (2018). Trayectorias, permanencias y continuidades de la competencia política y de los perfiles ideológicos de los partidos de derecha chilenos en la posdictadura. Tesis Doctoral, Universidad de Chile. http://repositorio. uchile.cl/handle/2250/173237

Gartenlaub-GonzÁlez, A. y Valenzuela, M. (2019). Los conservadores chilenos y la idea de familia: revisión historiográfica en tres etapas históricas. Política. Revista de Ciencia Política, 57(2), 29-54. https//:/ doi.org/10.5354/0719-5338.2019.61555

GutiÉRREZ, S. (2007). Análisis del discurso político: Un panorama del campo. En M. Gasca y M. E. Gómez (eds): Análisis del discurso: Perspectivas diversas (pp. 89-131). CELE, UNAM.

LARA, E. (2005 a). Sonaron siete balazos: Narcocorrido: objetivación y anclaje. Trayectorias, VII (17), 82-95. https://www.redalyc.org/pdf/607/60722 197009.pdf

LARA, E. (2005 b). El narcorrido como representación social. Revista Electrónica de Psicología Iztacala 8 (1). https://www.iztacala.unam.mx/carreras/ psicolo gia/psiclin/vol8num1/art3-n1-05.pdf

Madariaga, A. y Rovira Kaltwasser, C. (2020). Right-Wing Moderation, Left-Wing Inertia and Political Cartelisation in Post-Transition Chile. Journal of Latin American Studies, 52(2), 343-371. https://doi.org/10.1017/S0022216X19000932

Merry, M.K. (2019). Angels Versus Devils: The Portrayal of Characters in the Gun Policy Debate. Policy Study Journal, (47), 882-904. https://doi. org/10.1111/psj.12207

Ministerio de Salud (2020). Fases 3 y 4: Protocolo de recomendaciones para la Prevención y Atención del COVID-19. Gobierno de Chile, Servicio Nacional de Adulto Mayor. http://www.senama.gob. cl/storage/docs/-Fases_3_y_4_Protocolo_COVID-19_y_Personas_Mayores_-002.pdf

Montero, V., MuÑoz, C. y PICAZo, M. I. (2017). Estrategias y Recursos empleados por el movimiento estudiantil en el 2012. Universum, 32(1), 137-157. https:// doi.org/10.4067/S0718-23762017000100137

Morales, M. y Cantillana, C. (2008). ¿Me verás caer? La UDI frente a las municipales del 2008". Documento de trabajo 19. Observatorio Electoral. ICSO - Universidad Diego Portales.

Navarro, F. y Tromben, C. (2019): Estamos en guerra contra un enemigo poderoso, implacable: Ios discursos de Sebastián Piñera y la revuelta popular en Chile. Literatura y Lingüística, 40 (40), pp. 295 - 324. https://doi.org/10.29344/0717621X.40.2083

Paredes, J. P. y Otárola, C. (2019). El grito ciudadano en la lucha por el derecho a la educación: 
El marco moral y emocional de la movilización estudiantil en Chile (2011-2013). Sociológica, 98(34), 253-288. https://www.redalyc.org/journal/3050/305062704008/html/

Pérez, S. (2014). Análisis del discurso político. Editorial de la Facultad de Filosofía y Letras de la Universidad Nacional de Cuyo.

Ralón de Walton, G. (2014). La filosofía del quiasmo: Introducción al pensamiento de Merleau-Ponty. Diánoia, 59 (73), 170-177. https://doi.org/10.21898/ dia.v59i73.89

Segovia, C. y Gamboa, R. (2012). Chile el año que salimos a la calle. Revista de Ciencia Política, 32(1), 65-85. https://doi.org/10.4067/S0718090X2012000100004

VARAS, A. (2013). El gobierno de Piñera (2010-2014). La fronda aristocrática revivida. Catalonia.

\section{ANEXO: 27 DISCURSOS REVISADOS}

Prensa Presidencia. (2020, 13 de marzo). Presidente Piñera anuncia medidas por Coronavirus. Gobierno de Chile. https://prensa.presidencia.cl/ discurso.aspx?id=138176

Prensa Presidencia (2020, 16 de mayo). Presidente declara fase IV y anuncia cierre de fronteras. https://prensa.presidencia.cl/comunicado.aspx?id=148269

Prensa Presidencia (2020, 18 de marzo). Presidente Piñera decreta Estado de Excepción Constitucional de Catástrofe en todo el país por 90 días. https://prensa.presidencia.cl/comunicado.aspx?id=148647

Prensa Presidencia (2020, 1 de abril). Presidente Piñera promulga Ley de Protección de Empleo. https://prensa.presidencia.cl/comunicado.aspx?id=149347

Prensa Presidencia (2020, 1 de abril). Presidente Piñera anuncia acuerdo con Isapres para postergar alzas de planes de salud. Gobierno de Chile. https://prensa.presidencia.cl/comunicado.aspx?id=149392

Prensa Presidencia (2020, 8 de abril). Presidente Piñera anuncia segunda etapa del plan económico de emergencia. https://prensa.presidencia.cl/comunicado.aspx?id=149692

Prensa Presidencia (2020, 19 de abril). Presidente Piñera realiza cadena nacional para abordar situación en el país por coronavirus. Gobierno de
Chile. https://prensa.presidencia.cl/discurso. aspx?id=150322

Prensa Presidencia (2002, 17 de mayo). Presidente Piñera anuncias masivo paquete de ayuda para enfrentar la pandemia del Coronavirus y la crisis económica. https://prensa.presidencia.cl/ comunicado.aspx?id=151422

Prensa Presidencia (2020, 22 de mayo). Presidente Piñera pone en marcha programa "Alimentos para Chile". Gobierno de Chile. https://prensa. presidencia.cl/discurso.aspid=151583

Prensa Presidencia (2020, 29 de mayo). Presidente Piñera instruye acelerar entrega de canastas de suministros del plan "Alimentos para Chile. https://prensa.presidencia.cl/comunicado.aspx?id=152047

Prensa Presidencia. (2020, 30 de mayo). Presidente Piñera continúa desplegando el plan "Alimentos para Chile" en las comunas de la Región Metropolitana. Gobierno de Chile. https://prensa. presidencia.cl/discurso.aspx?id=151972

Prensa Presidencia. (2020, 2 de junio). Presidente Piñera revisa la llegada del vuelo que trae a Chile 133 ventiladores mecánicos y 400 equipos de oxigenoterapia de alto flujo. Gobierno de Chile. https://prensa.presidencia.cl/discurso.aspx?id=152091

Prensa Presidencia (2020, 13 de junio). Presidente Piñera nombra a Enrique Paris como nuevo Ministro de Salud. https://prensa.presidencia.cl/ comunicado.aspx?id=152505

Prensa Presidencia (2020, 14 de junio). Presidente Piñera presenta beneficios de acuerdo nacional por la protección social y recuperación de empleos. Gobierno de Chile. https://prensa.presidencia.cl/comunicado.aspx?id=152515

Prensa Presidencia (2020, 15 de junio). Presidente Piñera amplia Estado de Excepción Constitucional de catástrofe en todo el país. https://prensa. presidencia.cl/comunicado.aspx?id=152551

Prensa Presidencia (2020, 18 de junio). Presidente Piñera destaca ley que aumenta sanciones por incumplimiento de medidas sanitarias. Gobierno de Chile. https://prensa.presidencia.cl/discurso. aspx?id $=152616$

Prensa Presidencia (2020, 21 de junio). Presidente Piñera promulga nuevo Ingreso Familiar de Emergencia y ley con beneficios para trabajadores independientes: "Es un aporte muy necesario y urgente". Gobierno de Chile. https://prensa.presidencia.cl/discurso.aspx?id=152647

Prensa Presidencia (2020, 22 de junio). Presidente Piñera destaca la importancia del respeto a la 
Constitución. https://prensa.presidencia.cl/comunicado.aspx?id=152688

Prensa Presidencia (2020, 24 de junio). Presidente Piñera presenta proyecto de ley que beneficiará a padres, madres o cuidadores de niños en edad preescolar. https://prensa.presidencia.cl/ comunicado. aspx?id=152735

Prensa Presidencia. (2020, 25 de junio). Presidente Piñera visita instalaciones del Buque Sargento Aldea, que refuerza la red de salud de la Región de Valparaíso durante la emergencia del \#Covid-19: "No vamos a bajar los brazos y vamos a mantener la máxima alerta". Gobierno de Chile. https://prensa.presidencia.cl/comunicado.aspx?id=152747

Prensa Presidencia. (2020, 30 de junio). Presidente Piñera firma proyecto que amplía cobertura y beneficios de Ley de Protección del Empleo y del Seguro de Cesantía. https://prensa.presidencia.cl/comunicado.aspx?id=152770

Prensa Presidencia (2020, 3 de julio). Presidente Piñera destaca nuevo pago a beneficiarios del Ingreso Familiar de Emergencia. https://prensa. presidencia.cl/comunicado. aspx?id=152861

Prensa Presidencia (202, 3 de julio) Presidente Piñera promulga ley quie limita reelección de senadores, diputados, consejeros regionales, alcaldes y concejales. https://prensa.presidencia.cl/discurso.aspx?id=152868

Prensa Presidencia (2020, 5 de julio). Presidente Piñera anuncia plan de protección para la clase media con beneficios en vivienda, educación y financieros: "Necesita seguridades y oportunidades para el futuro". Gobierno de Chile. https://prensa. presidencia.cl/comunicado.aspx?id=153015

Prensa Presidencia (2020, 9 de julio). Presidente Piñera participa en conmemoración del día de la bandera nacional. https://prensa.presidencia. $\mathrm{cl} /$ discurso.aspx?id=153082

Prensa Presidencia (2020, 14 de julio). Presidente Piñera presenta nuevas medidas de apoyo para la clase media. https://prensa.presidencia.cl/ comunicado.aspx?id=153126

Prensa Presidencia (2020, 4 de octubre). Presidente celebra el legado de Patricio Aylwin en su centenario: "Hoy nos llamaría a ennoblecer la política, a buscar los caminos del diálogo y los acuerdos, a cultivar la amistad cívica". Gobierno de Chile. https://prensa.presidencia.cl/comunicado.aspx?id $=83518$ 